\begin{tabular}{|c|c|}
\hline $\begin{array}{l}\text { Chemistry of } \\
\text { Metals and Alloys }\end{array}$ & 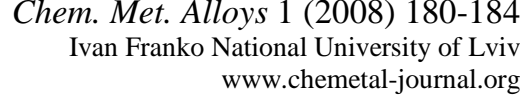 \\
\hline
\end{tabular}

\title{
Crystal structure of $\mathrm{K}-\mathrm{Hf}_{9} \mathrm{Mo}_{4} \mathrm{SiD}_{16.8}$ deuteride
}

\author{
I.V. KOVAL'CHUCK ${ }^{1}$, R. CERNY ${ }^{2}$, R.V. DENYS ${ }^{1}$, I.Yu. ZAVALIY ${ }^{1 *}$ \\ ${ }^{1}$ Physico-Mechanical Institute of NAS of Ukraine, 5 Naukova Str., 79601 Lviv, Ukraine \\ ${ }^{2}$ Laboratory of Crystallography, University of Geneva, 24 quai Ernest-Ansermet, CH-1211 Geneva 4, Switzerland \\ * Corresponding author.Tel.: +380-32-2296833; fax: +380-32-2649427; e-mail: zavaliy@ipm.lviv.ua
}

Received November 22, 2007; accepted May 20, 2008; available on-line September 10, 2008

The $\mathrm{\kappa}-\mathrm{Hf}_{9} \mathrm{Mo}_{4} \mathrm{SiD}_{16.8}$ deuteride was prepared by deuteration of the intermetallic alloy at room temperature and $0.1 \mathrm{MPa} \mathrm{D}_{2}$ pressure. Synchrotron X-ray and neutron powder diffraction studies revealed that the initial crystal structure is preserved upon deuterium absorption (sp.gr. P6 $/ m m c, a=8.9553(1), c=9.0947(2) \AA$, $\Delta a / a=4.0 \% ; \Delta c / c=5.5 \% ; \Delta V / V=14.1 \% ; \Delta V /$ at. $\left.\mathrm{D}=2.33 \AA^{3}\right)$. The deuterium atoms occupy four interstitial positions: two tetrahedral $\mathrm{Hf}_{2} \mathrm{Mo}_{2}$ and $\mathrm{Hf}_{3} \mathrm{Si}$ sites and two triangular $\mathrm{Hf}_{3}$ sites.

\section{Hafnium alloys / Hydrides / Crystal structure / X-ray and neutron diffraction analysis}

Introduction

Intermetallic $\kappa$-phases with $\mathrm{Hf}_{9} \mathrm{Mo}_{4} \mathrm{~B}$ structure type [1] were found in a number of ternary Hf-Mo-X systems (X= Si, P, S, Ge, As, Se) [2]. Phase analytical and crystallographic results indicate that $\mathrm{Hf} \rightarrow$ Mo substitution in the $6 h$ and $2 a$ sites is the cause of variations in the composition and lattice parameters $[3,4]$. In our previous work we have synthesised the $\mathrm{Zr}_{9} \mathrm{~V}_{4} \mathrm{SH}_{\sim 23}$ hydride and analysed the possible structure of its hydrogen sublattice. A neutron powder diffraction study of the $\mathrm{Zr}_{9} \mathrm{~V}_{4} \mathrm{SD}_{\sim 23}$ deuteride was carried out to localize the deuterium atoms [5]. A number of $\kappa$-phases, $\mathrm{Zr}_{9} \mathrm{Mo}_{4} \mathrm{NiO}_{\mathrm{x}}(\mathrm{x}=0 \div 3)$ and $\mathrm{Hf}_{9} \mathrm{Mo}_{4} \mathrm{Ge}$, as well as their hydrides, have been synthesized and characterised [6]. A comparison of the hydrogenation capacities of $\mathrm{Zr}_{9} \mathrm{Mo}_{4} \mathrm{NiO}_{\mathrm{x}}$ compounds with the $\mathrm{Zr}_{9} \mathrm{~V}_{4} \mathrm{SD}_{\sim 23}$ structural data allowed us to suggest that the presence of oxygen atoms in octahedral interstices blocks filling of $\mathrm{Zr}_{3}$ triangular faces by hydrogen atoms, thus decreasing the maximum hydrogen storage capacity by $25 \%$. In this work we present results on the preparation and crystal structure of the deuteride of the $\kappa-\mathrm{Hf}_{9} \mathrm{Mo}_{4} \mathrm{Si}$ phase.

\section{Experimental details}

A $\mathrm{Hf}_{9} \mathrm{Mo}_{4} \mathrm{Si}$ alloy was prepared by arc melting of the constituent elements followed by high temperature annealing in an evacuated quartz ampoule $\left(1170^{\circ} \mathrm{C}\right.$, $5 \mathrm{~h}$ ). The deuteride of this alloy was synthesised by gas-solid reaction at room temperature and $0.1 \mathrm{MPa}$ $\mathrm{D}_{2}$ pressure. The deuterium content was measured by a standard volumetric technique. The parent and deuterated alloys were examined by X-ray powder diffraction (DRON-3.0, $\mathrm{Cu}-\mathrm{K} \alpha$ radiation and Bruker $\mathrm{D} 8, \mathrm{Cu}-\mathrm{K} \alpha_{1}$ radiation). The crystal structure of the deuteride was determined by a joint Rietveld refinement of synchrotron X-ray (SNBL, ESRF, France, $\lambda=0.3748 \AA$ ) and neutron powder diffraction data (Paul Scherrer Institute, Switzerland, HRPT instrument, $\lambda=1.494 \AA$ A) using GSAS software [7].

Results and discussion

The $\kappa-\mathrm{Hf}_{9} \mathrm{Mo}_{4} \mathrm{Si}$ phase with $\mathrm{Hf}_{9} \mathrm{Mo}_{4} \mathrm{~B}$ structure type was found as the main constituent phase in the parent alloy. The presence of $\mathrm{Hf}_{2} \mathrm{Si}$ (sp.gr. I4/ $\mathrm{mcm}$, $a=6.5268(8), c=5.212(1) \AA$ ), $\mathrm{HfMo}_{2}$ (sp.gr. $F d-3 m$, $a=7.5696(6) \AA$ ), and $\beta-\mathrm{Hf}_{0.7} \mathrm{Mo}_{0.3}$ (sp.gr. Im-3m, $a=3.4167(3) \AA$ ) as additional phases is in agreement with the phase diagram of the Hf-Mo-Si system. The content of the $\kappa-\mathrm{Hf}_{9} \mathrm{Mo}_{4} \mathrm{Si}$ phase in the parent alloy was $\sim 60 \mathrm{wt} . \%$ according to the Rietveld refinement of the powder X-ray diffraction (XRD) data. XRD profiles of the parent alloy are presented in Fig. 1 and the corresponding crystal structure data for the main $\kappa-\mathrm{Hf}_{9} \mathrm{Mo}_{4} \mathrm{Si}$ phase are described in Table 1.

The hydrogen (deuterium) absorption capacity of the alloy obtained by volumetric measurements was $1.12 \mathrm{D} / \mathrm{M}$ ( $\mathrm{M}=\mathrm{Hf}$, Mo and $\mathrm{Si}$ ). The analysis of the powder diffraction data showed that all the constituent phases formed corresponding deuterides. A multiphase Rietveld refinement on synchrotron and neutron diffraction data (Fig. 2) showed the following phase composition of the deuterated alloy: $\mathrm{Hf}_{9} \mathrm{Mo}_{4} \mathrm{SiD}_{16.8}(57.1(1)$ wt.\%); 
Table 1 Crystallographic parameters of $\kappa-\mathrm{Hf}_{9} \mathrm{Mo}_{4} \mathrm{Si}$.

Sp.gr. $P 6_{3} / m m c, a=8.6116(6), c=8.6188(8) \AA, V=553.53(8) \AA^{3}$.

\begin{tabular}{l|l|l|l|l}
\hline Atom & Site & $x / a$ & $y / b$ & $z / c$ \\
\hline Hf1 & $6 h$ & $0.5386(6)$ & $0.0772(12)$ & $1 / 4$ \\
Hf2 & $12 k$ & $0.1994(4)$ & $0.3988(8)$ & $0.0522(6)$ \\
Mo1 & $2 a$ & 0 & 0 & 0 \\
Mo2 & $6 h$ & $0.8914(8)$ & $0.7828(16)$ & $1 / 4$ \\
Si & $2 c$ & $1 / 3$ & $2 / 3$ & $1 / 4$ \\
\hline
\end{tabular}

Note: atomic displacement parameters $U_{\text {iso }}$ for all atoms were set to $0.005 \AA^{2}$.

Table 2 Crystallographic parameters of the $\mathrm{Hf}_{9} \mathrm{Mo}_{4} \mathrm{SiD}_{16.8}$ deuteride (filled $\mathrm{Hf}_{9} \mathrm{Mo}_{4} \mathrm{~B}$ type). Sp.gr. $P 6_{3} / m m c, a=8.9553(1), c=9.0947(2) \AA, V=631.66(4) \AA^{3}$.

\begin{tabular}{l|l|c|l|l|l|l|l}
\hline Atom & Site & Surrounding & $x / a$ & $y / b$ & $z / c$ & $U_{i s o} \times 100\left(\AA^{2}\right)$ & Occupation \\
\hline Hf1 & $6 h$ & - & $0.5401(1)$ & $0.0802(2)$ & $1 / 4$ & $0.73(2)$ & $1.0(-)$ \\
Hf2 & $12 k$ & - & $0.20185(8)$ & $0.4037(2)$ & $0.0526(1)$ & $=U_{\text {iso }}(\mathrm{Hf} 1)$ & $1.0(-)$ \\
Mo1 & $2 a$ & - & 0 & 0 & 0 & $1.10(6)$ & $1.0(-)$ \\
Mo2 & $6 h$ & - & $0.8958(2)$ & $0.7916(3)$ & $1 / 4$ & $=U_{\text {iso }}(\mathrm{Mo} 1)$ & $1.0(-)$ \\
Si & $2 c$ & - & $1 / 3$ & $2 / 3$ & $1 / 4$ & $1.7(3)$ & $1.0(-)$ \\
D1 & $24 l_{1}$ & T: Hf1Hf2 ${ }_{2} \mathrm{Mo} 2$ & $0.3383(4)$ & $0.0419(3)$ & $0.1251(3)$ & $1.61(5)$ & $0.816(6)$ \\
D3 & $2 d$ & $\Delta: \mathrm{Hf}_{3}$ & $1 / 3$ & $2 / 3$ & $3 / 4$ & $=U_{\text {iso }}(\mathrm{D} 1)$ & $0.999(17)$ \\
D4 & $12 k_{4}$ & T: Hf1Hf2 2 Si & $0.428(1)$ & $0.572(1)$ & $0.148(2)$ & $=U_{\text {iso }}(\mathrm{D} 1)$ & $0.219(5)$ \\
D5 & $12 k_{5}$ & $\Delta:$ Hf1Hf2 2 & $0.5862(2)$ & $0.1724(5)$ & $0.0470(5)$ & $=U_{\text {iso }}(\mathrm{D} 1)$ & $0.781(5)$ \\
\hline
\end{tabular}

Note: T: tetrahedral, $\Delta$ : triangular interstices.

Table 3 Crystallographic parameters of $\mathrm{Hf}_{2} \mathrm{SiD}$ (filled $\mathrm{CuAl}_{2}$ type).

Sp.gr. $I 4 / m c m, a=6.5126(2), c=5.4124(3) \AA, V=229.56(2) \AA^{3}$.

\begin{tabular}{l|l|c|l|l|l|l|l}
\hline Atom & Site & Surrounding & $x / a$ & $y / b$ & $z / c$ & $U_{i s o} \times 100\left(\AA^{2}\right)$ & Occupation \\
\hline $\mathrm{Hf}$ & $8 h$ & - & $0.1649(2)$ & $0.6649(2)$ & 0 & $0.20(3)$ & $1.0(-)$ \\
$\mathrm{Si}$ & $4 a$ & - & 0 & 0 & $1 / 4$ & $0.7(2)$ & $1.0(-)$ \\
$\mathrm{D}$ & $4 b$ & $\mathrm{~T}: \mathrm{Hf}_{4}$ & 0 & $1 / 2$ & $1 / 4$ & $2.8(2)$ & $1.02(2)$ \\
\hline
\end{tabular}

Table 4 Crystallographic parameters of $\mathrm{HfMo}_{2} \mathrm{D}_{1.3}$ (cubic Laves phase deuteride).

Sp.gr. $F d-3 m$ [setting 2], $a=7.6799(2) \AA, V=452.97(2) \AA^{3}$.

\begin{tabular}{l|l|c|l|l|l|l|l}
\hline Atom & Site & Surrounding & $x / a$ & $y / b$ & $z / c$ & $U_{i s o} \times 100\left(\AA^{2}\right)$ & Occupation \\
\hline Hf & $8 b$ & - & $3 / 8$ & $3 / 8$ & $3 / 8$ & $1.52(6)$ & $1.0(-)$ \\
Mo & $16 c$ & - & 0 & 0 & 0 & $1.24(6)$ & $1.0(-)$ \\
D & $96 g$ & $\mathrm{~T}: \mathrm{Hf}_{2} \mathrm{Mo}_{2}$ & $0.203(2)$ & $0.547(2)$ & $0.370(2)$ & $2.5(5)$ & $0.109(6)$ \\
\hline
\end{tabular}

Table 5 Crystallographic parameters of $\mathrm{Hf}_{0.7} \mathrm{Mo}_{0.3} \mathrm{D}_{1.7}\left(\varepsilon-\mathrm{ZrH}_{2}\right.$ type).

Sp.gr. I4/mmm, $a=3.3046(4), c=4.4940(9) \AA, V=49.07(1) \AA^{3}$.

\begin{tabular}{l|l|c|l|l|l|l|l}
\hline Atom & Site & Surrounding & $x / a$ & $y / b$ & $z / c$ & $U_{i s o} \times 100\left(\AA^{2}\right)$ & Occupation \\
\hline $\mathrm{M}$ & $2 a$ & - & 0 & 0 & 0 & $1.06(7)$ & $0.73 \mathrm{Hf}+0.27 \mathrm{Mo}$ \\
$\mathrm{D}$ & $4 d$ & $\mathrm{~T}: \mathrm{M}_{4}$ & 0 & $1 / 2$ & $1 / 4$ & $2.0(-)$ & $0.86(2)$ \\
\hline
\end{tabular}

$\mathrm{Hf}_{2} \mathrm{SiD}\left(13.0(1)\right.$ wt.\%), $\mathrm{HfMo}_{2} \mathrm{D}_{1.3}$ (14.7(1) wt.\%) and $\mathrm{Hf}_{0.7} \mathrm{Mo}_{0.3} \mathrm{D}_{1.7}(15.2(1) \mathrm{wt} . \%)$. The total hydrogenation capacity, calculated from these data, is $1.02 \mathrm{D} / \mathrm{M}$, which is close to the result of the volumetric measurements. The obtained crystal structure data are summarized in Tables 2-5. The crystal structure of the $\kappa-\mathrm{Hf}_{9} \mathrm{Mo}_{4} \mathrm{SiD}_{16.8}$ deuteride is shown in Fig. 3.

Similarly to other studied $\kappa$-phase hydrides $[5,6]$, $\mathrm{Hf}_{9} \mathrm{Mo}_{4} \mathrm{SiD}_{16.8}$ preserves the initial symmetry of the metal matrix. The relative changes in the unit cell parameters during its formation $(\Delta a / a=4.0 \%$; $\Delta c / c=5.5 \% ; \Delta V / V=14.1 \% ; \Delta V /$ at.D $\left.=2.33 \AA^{3}\right)$ are comparable to those of $\mathrm{Zr}_{9} \mathrm{Mo}_{4} \mathrm{NiO}_{\mathrm{x}} \mathrm{H}_{\mathrm{y}}$ and $\mathrm{Hf}_{9} \mathrm{Mo}_{4} \mathrm{GeH}_{16.0}$ [6], which may indicate similarities of the hydrogen sublattice of these hydrides. An analysis of the types of interstitial site available for hydrogen insertion and the possible models for the hydrogen sublattice of $\kappa$-phase hydrides was performed in [5]. The refinement on neutron diffraction data allowed us to locate four crystallographic sites occupied by D 
I.V. Koval'chuck et al., Crystal structure of $\kappa-\mathrm{Hf}_{9} \mathrm{Mo}_{4} \mathrm{SiD}_{16.8}$ deuteride

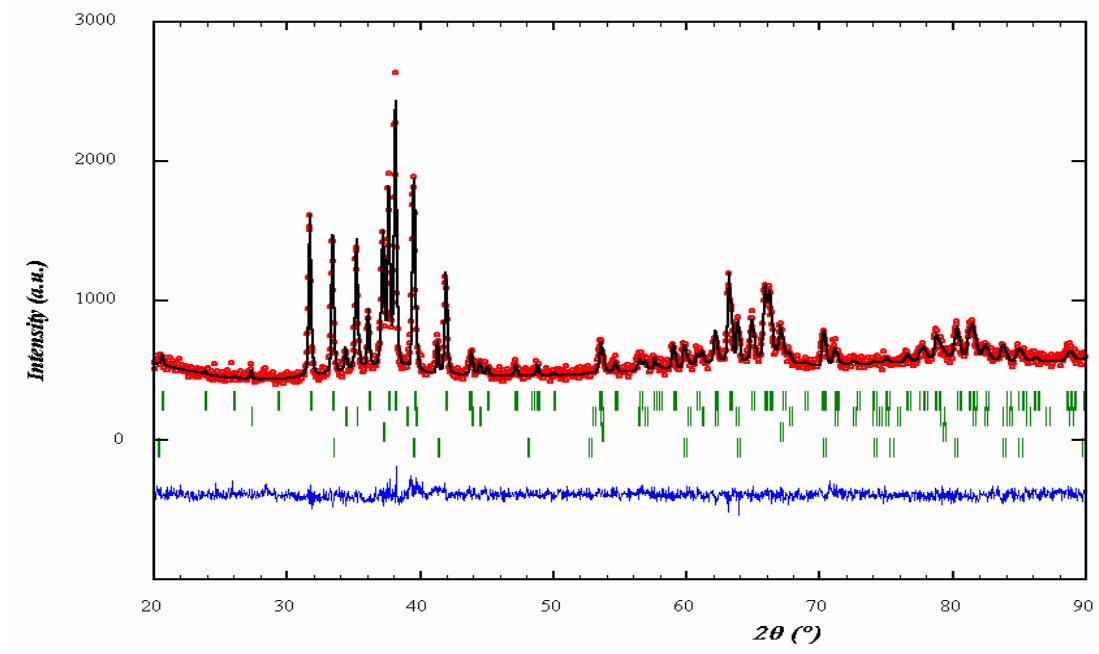

Fig. 1 Observed (+), calculated (line) and difference (bottom line) X-ray powder diffraction patterns of the parent alloy. Vertical bars indicate Bragg positions of the constituent phases (from top to bottom): $\mathrm{Hf}_{9} \mathrm{Mo}_{4} \mathrm{Si}$, $\mathrm{Hf}_{2} \mathrm{Si}, \mathrm{Hf}_{0.7} \mathrm{Mo}_{0.3}$ and $\mathrm{HfMo}_{2} . R$-factors of the refinement: $R_{w p}=4.73 \%, R_{p}=3.74 \%, \chi^{2}=1.35$.

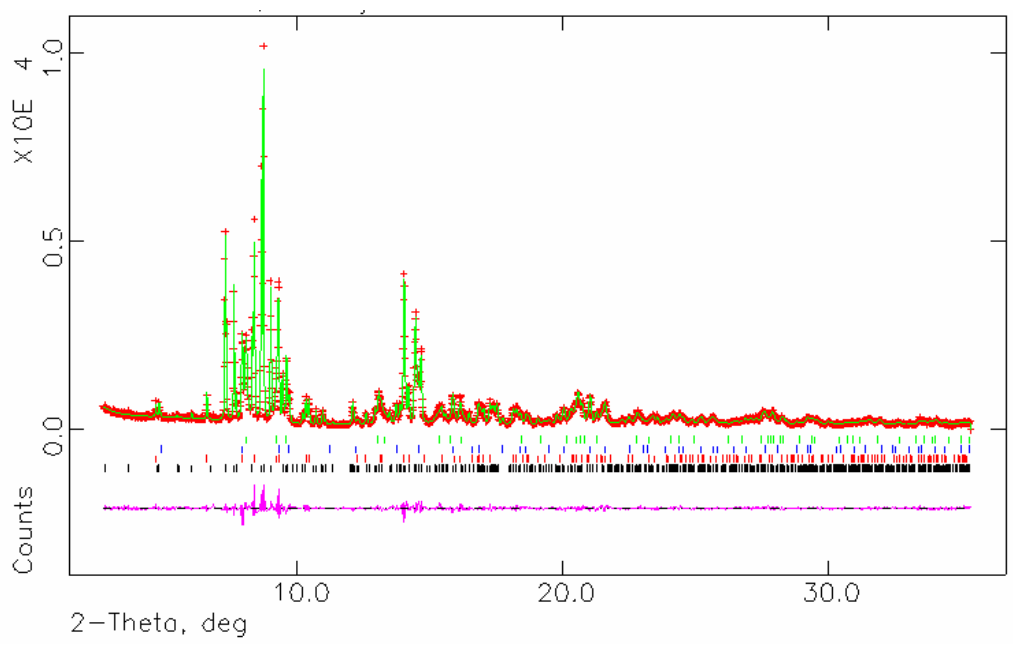

(a)

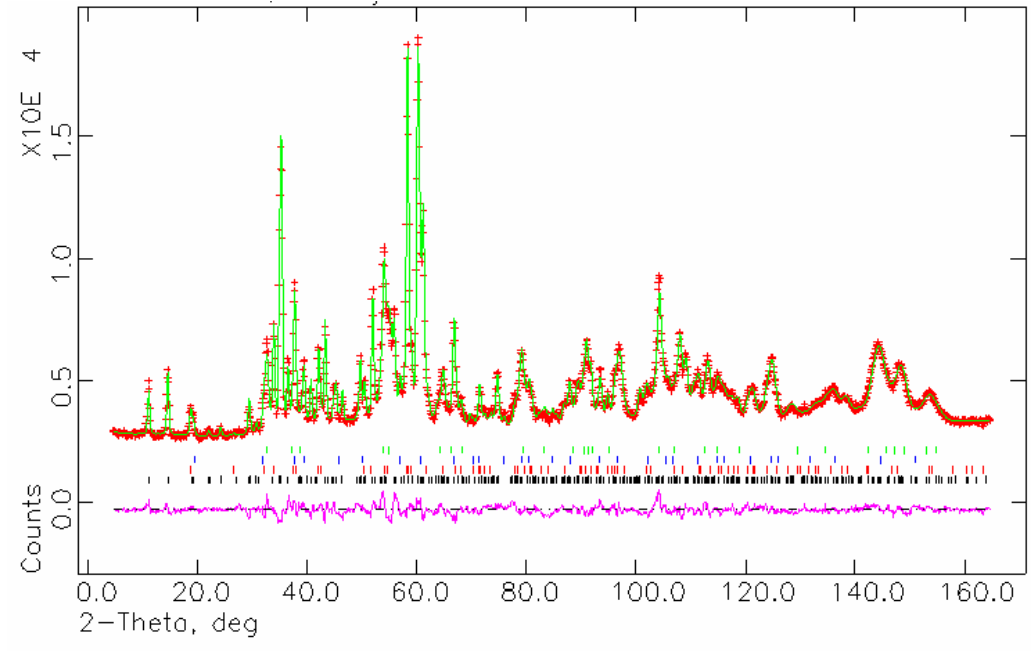

(b)

Fig. 2 Observed (+), calculated (line) and difference (bottom line) SRXRD (a) and PND (b) patterns of the deuterated alloy. Vertical bars indicate Bragg positions of the constituent phases (from bottom to top): $\mathrm{Hf}_{9} \mathrm{Mo}_{4} \mathrm{SiD}_{16.8} ; \mathrm{Hf}_{2} \mathrm{SiD} ; \mathrm{HfMo}_{2} \mathrm{D}_{1.5}$ and $\mathrm{Hf}_{0.7} \mathrm{Mo}_{0.3} \mathrm{D}_{1.7} . R$-factors: PND: $R_{w p}=3.53 \%, R_{p}=2.72 \%$; SXRD: $R_{w p}=7.37 \%, R_{p}=5.90 \%$; combined: $R_{w p}=5.94 \%, R_{p}=3.99 \% ; \chi^{2}=2.95$. 


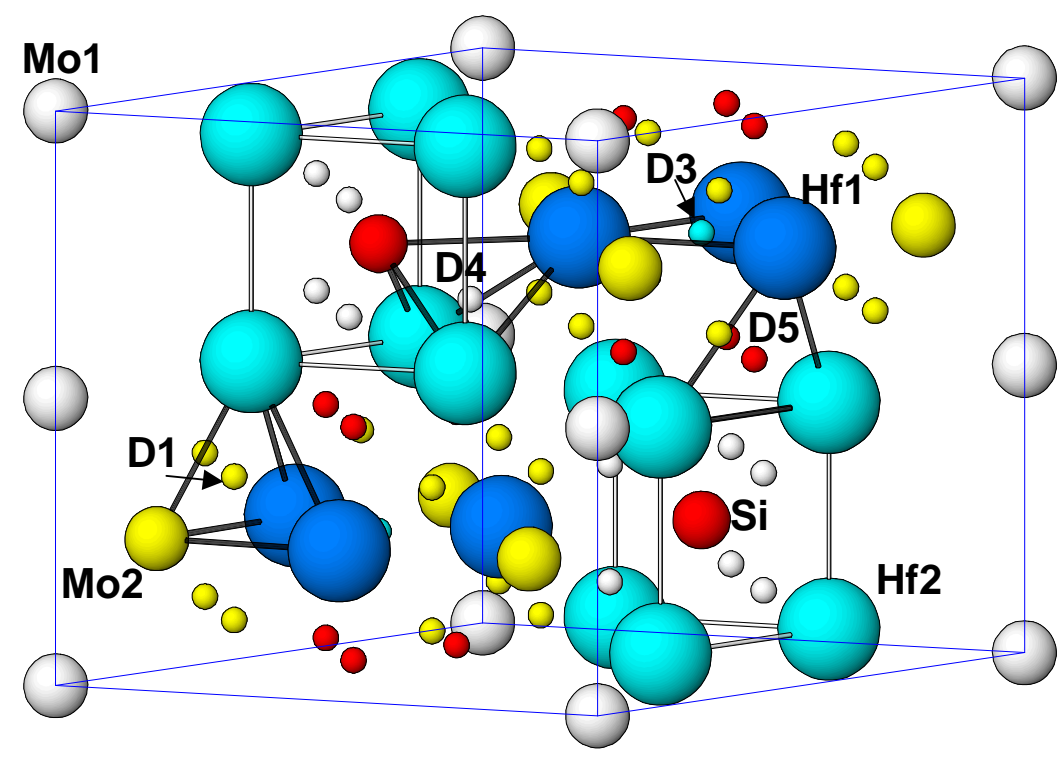

Fig. 3 Crystal structure of $\kappa-\mathrm{Hf}_{9} \mathrm{Mo}_{4} \mathrm{SiD}_{16.8}$.

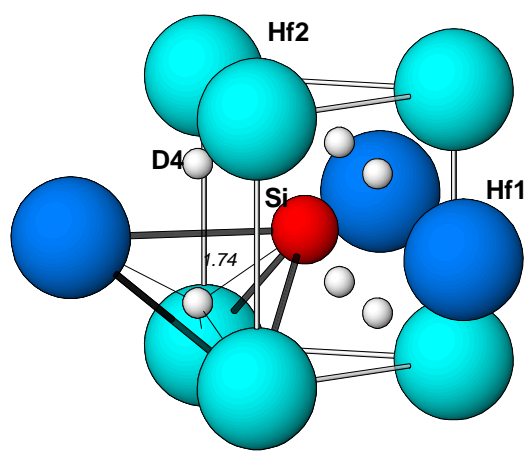

D4...Si $=1.74 \AA$

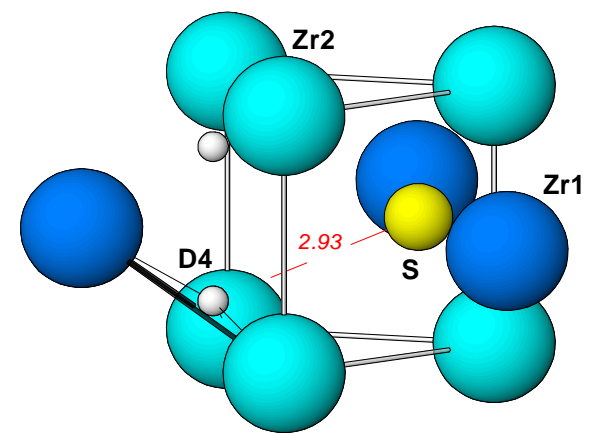

D4...S $=2.93 \AA$

$S$ atom shifts from initial $2 c$ site to $6 h$ site (occupied by $1 / 3$ )

Fig 4 Comparison of structure fragments of $\mathrm{Hf}_{9} \mathrm{Mo}_{4} \mathrm{SiD}_{16.8}$ (left) and $\mathrm{Zr}_{9} \mathrm{~V}_{4} \mathrm{SD}_{\sim 23}$ (right).

atoms (see Table 2, the D sites are labelled according to [5]). Contrary to the $\mathrm{Zr}_{9} \mathrm{~V}_{4} \mathrm{SD}_{\sim 23}$ structure, the $\mathrm{D} 2$ site $\left(\mathrm{HfMo}_{3}\right.$ interstice, which corresponds to $\mathrm{ZrV}_{3}$ in $\mathrm{Zr}_{9} \mathrm{~V}_{4} \mathrm{SD}_{\sim 23}$ ) is vacant, which can be explained by the smaller hydrogen affinity of Mo compared to $\mathrm{V}$. Another difference between the structures of $\mathrm{Hf}_{9} \mathrm{Mo}_{4} \mathrm{SiD}_{16.8}$ and $\mathrm{Zr}_{9} \mathrm{~V}_{4} \mathrm{SD}_{\sim 23}$ [5] is that the atoms of the $p$-element $(\mathrm{Si})$ in $\mathrm{Hf}_{9} \mathrm{Mo}_{4} \mathrm{SiD}_{16.8}$ remain in the initial position, whereas the sulphur atoms are shifted from the 3 -fold axis ( $2 c$ position) by $1.1 \AA$ into a $6 h$ position, filled by $1 / 3$. (see Fig. 4). Such a displacement is attributed to a repulsive deuteriumsulphur interaction (all observed deuterium-sulphur distances are longer than $2.9 \AA$ ), and allows the filling of $\mathrm{Hf}_{3}$ faces (D4) by deuterium. The $\mathrm{D} 4$ atom in the structure of $\mathrm{Hf}_{9} \mathrm{Mo}_{4} \mathrm{SiD}_{16.8}$ is shifted from the triangular $\mathrm{Hf}_{3}$ face towards a $\mathrm{Si}$ atom and occupies the centre of a $\mathrm{Hf}_{3} \mathrm{Si}$ tetrahedron. Thus, we observe direct contact between the $p$-element and deuterium $\left(d_{\text {D4-D5 }}=1.74(2) \AA\right)$.

The D4 site is occupied by $22 \%$ only due to selfblocking $\left(d_{\mathrm{D} 4-\mathrm{D} 4}=1.85(3) \AA\right)$ and filling of the neighbouring D5 position $\left(d_{\mathrm{D} 4-\mathrm{D} 5}=1.79(2) \AA\right)$. The sum of the occupancy factors of the D4 and D5 sites cannot exceed unity. The D1 and D3 sites do not have any $\mathrm{D}$ sites in their nearest surrounding and can be filled up completely. However, a full occupancy of only the D3 site is observed, giving a refined deuterium content of 16.8(1) D/f.u. The maximum possible capacity of the deuteride, taking into account blocking between the D4 and D5 sites, is 19 D/f.u. The distances between $\mathrm{D}$ atoms and the metal/silicon atoms in their surrounding are presented in Table 6 . They are in agreement with the sum of the radii of these atoms. The separation between the nearest deuterium atoms in the $\mathrm{Hf}_{9} \mathrm{Mo}_{4} \mathrm{SiD}_{16.8}$ structure exceeds $2 \AA$.

\section{Conclusions}

The $\mathrm{Hf}_{9} \mathrm{Mo}_{4} \mathrm{SiD}_{16.8}$ deuteride has been synthesized. The crystal structure of this deuteride has been studied by synchrotron X-ray and neutron powder diffraction. 
I.V. Koval'chuck et al., Crystal structure of $\kappa-\mathrm{Hf}_{9} \mathrm{Mo}_{4} \mathrm{SiD}_{16.8}$ deuteride

Table 6 Selected interatomic distances in the structure of $\mathrm{Hf}_{9} \mathrm{Mo}_{4} \mathrm{SiD}_{16.8}$.

\begin{tabular}{l|l|l|l}
\hline Atoms & $d, \AA$ & Atoms & $d, \AA$ \\
\hline Hf1... D1 & $2.013(3)$ & Hf2..2 D1 & $2.042(3)$ \\
Hf1... 3 & $1.963(2)$ & Hf2..2 D5 & $1.998(2)$ \\
Hf1..2 D5 & $1.980(4)$ & Hf2..2 D4 & $2.019(8)$ \\
Hf1..2 D4 & $1.97(2)$ & Mo2..4 D1 & $1.898(3)$ \\
Hf2...2 D1 & $2.007(3)$ & Si...6 D4 & $1.74(2)$ \\
\hline
\end{tabular}

The $\mathrm{Hf}_{2} \mathrm{SiD}, \mathrm{HfMo}_{2} \mathrm{D}_{1.3}$ and $\mathrm{Hf}_{0.7} \mathrm{Mo}_{0.3} \mathrm{D}_{1.7}$ deuterides were found as additional phases. It has been shown that $\kappa-\mathrm{Hf}_{9} \mathrm{Mo}_{4} \mathrm{SiD}_{16.8}$ belongs to the filled $\mathrm{Hf}_{9} \mathrm{Mo}_{4} \mathrm{~B}-$ type structure (sp.gr. $P 6_{3} / m m c, \quad a=8.9553(1) \AA$, $c=9.0947(2) \quad \AA, \quad \Delta a / a=4.0 \% ; \quad \Delta c / c=5.5 \%$; $\Delta V / V=14.1 \% ; \Delta V /$ at. $\mathrm{D}=2.33 \AA^{3}$ ). The deuterium atoms occupy four crystallographic positions: two types of tetrahedral interstice, $\mathrm{Hf} 1 \mathrm{Hf} 2{ }_{2} \mathrm{Mo} 2$ and Hf1 $1 \mathrm{Hf} 2_{2} \mathrm{Si}$; and two types of triangular face, $\mathrm{Hf}_{3}$ and $\mathrm{Hf}_{1 \mathrm{Hf}} 2_{2}$.

\section{Acknowledgements}

This work was supported by YSF INTAS grant Ref.No:06-1000019-6490. The help of Denys Sheptyakov (Paul Scherrer Institute, Switzerland) with the neutron powder diffraction experiment is highly appreciated.

\section{References}

[1] P. Rogl, H. Nowotny, F. Benesowsky, Monatsh. Chem. 104 (1973) 182.

[2] A. Harsta, J. Solid State Chem. 57 (1985) 362.

[3] R. Mackay, H.F. Franzen, New Zirconium Kappa Phases, Z. Anorg. Allg. Chem. 616 (1992) 154-156.

[4] G.A. Marking, V.G. Young, H.F. Franzen, New group V א-phases, J. Alloys Compd. 241 (1996) 98-111.

[5] I.Yu. Zavaliy, R. Černý, I.V. Koval'chuck, A.B. Riabov, R.V. Denys, J. Alloys Compd. 404406 (2005) 118-121.

[6] I. Koval'chuck, I. Zavaliy, A. Riabov, Visn. L'viv. Univ., Ser. Khim. 46 (2005) 90-95.

[7] A.C. Larson, R.B. Von Dreele, General Structure Analysis System (GSAS), Los Alamos National Laboratory Report LAUR 86-748, 2004.

Proceeding of the X International Conference on Crystal Chemistry of Intermetallic Compounds,

Lviv, September 17-20, 2007. 